\title{
Observational study of continuity of HIV care following release from correctional facilities in South Africa
}

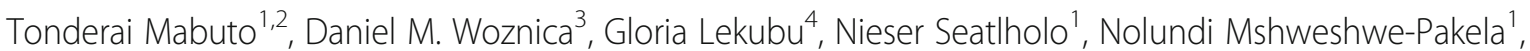
Salome Charalambous ${ }^{1,2}$ and Christopher J. Hoffmann ${ }^{1,3,5^{*}}$ (D)

\begin{abstract}
Background: We sought to describe linkage to care, ART continuity, and factors associated with linkage to care among people with HIV following release from incarceration in South Africa.

Methods: We conducted a study of South African correctional service community reentrants who were receiving ART at the time of release. The study was implemented in three of 46 correctional service management areas. Participants were enrolled prior to corrections release and followed up to 90 days post-release to obtain selfreported linkage to care status and number of days of ART provided at corrections release. Clinic electronic and paper charts were sought and abstracted to verify self-reported linkage to care. Log-binomial regression, adjusted for facility, was used to identify associations with post-release linkage to care (self-reported and verified). We sought to specifically assess for associations with HIV diagnosis during index incarceration, ART initiation during index incarceration, and duration of incarceration.

Results: From May 2014 to December 2016, 554 inmates met eligibility and 516 (93\%) consented to participate; 391 were released on ART, 40 of whom were excluded from analysis post-release. Of the remaining 351, 301 (86\%) were men and the median age was 35 years (interquartile range 30, 40). Linkage to care was self-reported by 227 (64\%) and linkage to care could be verified for 121 (34\%). At most, 47\% of participants had no lapse in ART supply. Initiating ART during the index incarceration showed a trend toward increased self-reported post-release linkage to care. Age > 35 years was associated with increased verified linkage to care while HIV diagnosis outside of a correctional setting and ART initiation during the index incarceration showed trends toward association with increased verified linkage to care.

Discussion: The results of our study are the first description of retention in care following correctional facility release from an African setting and indicate high levels of attrition during the transition from correctional facility to community care. Initiating ART within a correctional facility did not impair post-release linkage to care.
\end{abstract}

Keywords: HIV, Linkage to care, Prison, Africa, Antiretroviral therapy

\footnotetext{
* Correspondence: choffmann@jhmi.edu

'Aurum Institute, Johannesburg, South Africa

${ }^{3}$ Johns Hopkins University Bloomberg School of Public Health, Baltimore,

USA

Full list of author information is available at the end of the article
}

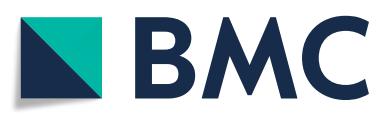

(c) The Author(s). 2020 Open Access This article is licensed under a Creative Commons Attribution 4.0 International License, which permits use, sharing, adaptation, distribution and reproduction in any medium or format, as long as you give appropriate credit to the original author(s) and the source, provide a link to the Creative Commons licence, and indicate if changes were made. The images or other third party material in this article are included in the article's Creative Commons licence, unless indicated otherwise in a credit line to the material. If material is not included in the article's Creative Commons licence and your intended use is not permitted by statutory regulation or exceeds the permitted use, you will need to obtain permission directly from the copyright holder. To view a copy of this licence, visit http://creativecommons.org/licenses/by/4.0/ The Creative Commons Public Domain Dedication waiver (http://creativecommons.org/publicdomain/zero/1.0/) applies to the data made available in this article, unless otherwise stated in a credit line to the data. 


\section{Introduction}

Criminal justice involved populations are recognized to be at risk for HIV infection and, if living with HIV, to have challenges along the HIV care continuum [1]. In many regions of the world, correctional centers concentrate large numbers of persons with HIV or at risk for HIV infection. In southern African correctional facilities, the reported prevalence of HIV infection among inmates ranges from $7.2-35 \%$ compared to $4.7-19 \%$ for the corresponding country-level general population prevalence $[2,3]$. Correctional centers in southern Africa may provide a gateway to HIV treatment and prevention services to a predominantly younger male population, a population that normally exhibits lower engagement in health care [4-7]. Once diagnosed with HIV, inmates in correctional facilities in South Africa are likely to initiate antiretroviral therapy (ART) and achieve favorable treatment outcomes $[8,9]$.

The proportion of inmates released on ART who link to community clinics post-release is poorly described in South Africa and elsewhere in Africa. There are no descriptions of the potential effect of ART initiation during incarceration on subsequent linkage to care. Most studies on this transition, to date, are from the United States. These studies have reported post-release linkage to care from 28 to $95 \%$ with a median reported in a metaanalysis of $36 \%$ [10-15]. Differences in care delivery, the criminal justice system, and the social fabric in South Africa compared to the United States may lead to differences in retention in care following corrections release. Thus estimating local linkage to care is important. We sought to estimate linkage to care and ART continuity following release and assess for factors associated with linkage among people on ART leaving correctional facilities in South Africa.

\section{Methods \\ Setting}

The study was implemented in the Gauteng Region of South Africa, one of the six administrative regions of the South Africa Department of Correctional Services (DCS). Three management areas (Modderbee, Kgosi Mampuru II, and Baviaanspoort) were selected to provide a range in size of the inmate population, level of security, men and women, those awaiting trial, and sentenced offenders. The daily census across the participating study sites was approximately 14,000 inmates; $29 \%$ were awaiting trial. The inmate population in correctional facilities in South Africa is $98 \%$ men and $79 \%$ black African [16]. Information on the median sentence duration and estimated HIV prevalence in each study facility was not available. All participating facilities had on-site routine ART programs available to all inmates meeting South African national eligibility criteria at the time of the study enrollment (2014-2016). Prior to release, correctional health staff prepared a referral letter for the reentrant to take to a community-based primary health care clinic. In addition, a supply of ART was provided to last between 15 and 90 days [17].

\section{Study design}

Observational study of linkage to care following corrections release.

\section{Participants}

Inmates were eligible to participate if they were receiving HIV-related care at one of the study sites. Additional inclusion criteria were: $\geq 18$ years old, capable of providing informed consent, known or anticipated release date within the study period, anticipated release residence within Gauteng Province, and willingness to provide telephonic or residential contact details to facilitate follow-up activities. In this report we only included participants receiving ART at the time of release. This decision was made because the on-ART population has the most relevance for current South African HIV care models of providing ART to all people with HIV. Study staff based at each of the participating sites worked with the correctional facility health staff and inmate peer educators to recruit and identify inmates who met the eligibility criteria. Those who met eligibility criteria and were interested in participating were provided written and verbal information in their language of choice and enrolled into the study. All participants completed written informed consent prior to enrollment.

This study was conducted according to the principles expressed in the Declaration of Helsinki. Human subject research approval was obtained from the University of the Witwatersrand Human Research Ethics Committee (M120492), the South African Department of Correctional Services Research Review Committee, the Johns Hopkins Medicine Institutional Review Board (NA 83335), and the CDC Institutional Review Board.

\section{Procedures}

Baseline characteristics, including age, sex, duration of incarceration, whether HIV was diagnosed in the correctional facility, and whether ART with initiated in the correctional facility were obtained through structured interviews conducted by research team members while the participant was still incarcerated. The research team members also recorded locator information, including cell phone number, alternative numbers, and location of anticipated residence upon release. Correctional facility health service routine medical records were abstracted onto structured report forms to record the date and result of any CD4 count testing performed closest to the date of release. 
Follow-up data collection occurred through structured interviews conducted by research team members. These interviews were conducted either telephonically or inperson. Participants were contacted telephonically at 15 days post-release to verify locator information and starting at 30 days to ascertain post-release care status. These calls were repeated at 60 days and again at 90 days if contact was unsuccessful or linkage not reported during the prior call. The primary purpose of the interviews was to ascertain linkage to care status. Telephonic contact was attempted at least three times, at different times of the day and on different days (including weekends). When telephonic contact was unsuccessful, home visits were attempted in collaboration with DCS community corrections staff. At least three attempts were made to visit the reported place of residence.

Among participants reporting linkage to care, the clinic at which a participant reported receiving care was visited; if no records were located, the participant was contacted again to ask whether they entered care and at which clinic, and to inquire regarding any different names that may have been used to register for care. Records from routine clinical care in public clinics were abstracted to verify self-reported linkage. Local clinics used a mix of electronic care registries, electronic laboratory results, and paper-based charts for patient care and statistical reporting. All three sources were used for verification of self-reported linkage to care. Paper and electronic clinical records were matched to a participant based on name, date of birth, and a range of service dates.

\section{Measures}

\section{Outcomes}

The primary outcome was the proportion of participants with self-reported linkage to care within 90 days of release. Secondary outcomes were the proportion of participants with verified linkage to care within 90 days of release and the proportion of participants without a lapse in ART possession following release.

- Self-reported linkage to care: This was defined as a participant having reported, during follow-up contact, attending a clinic for HIV care subsequent to release. Participants who were unable to be contacted were considered not to have linked to care.

- Verified linkage to care: This was defined as a confirmation of self-reported linkage to care. Linkage was confirmed using abstracted clinic-based paper or electronic records.

- Lapse in ART possession: This was based on the self-reported date of first linkage to care and the self-reported days of ART provided at corrections release. A lapse was defined to have occurred if the time to first clinic visit from corrections release was greater than the reported medication supply received at corrections release. If there was no selfreported linkage to care a participant was also classified as having a lapse in ART possession.

\section{Independent variables}

We assessed independent variables for association with the primary outcome of self-reported linkage to care and the secondary outcome of verified linkage to care. We specifically included the following variables in bivariate modeling: sex, age group $(<35, \geq 35$ years old), CD4 count, duration of incarceration, location of HIV diagnosis, and location of ART initiation. The age group was divided at age 35 years based on a prior study from South Africa reporting generally lower linkage to care from community HIV testing among individuals $<35$ years old [6]. Sex and age were selected as independent variables based on the evidence that each is associated with linkage to care. Incarceration duration and location of HIV diagnosis and ART initiation were included to assess for associations with corrections specific factors that may be associated with linkage to care. We were particularly interested in assessing whether place of ART initiation (while incarcerated or prior to incarceration) affected post-release linkage to care.

\section{Statistical analysis}

We excluded from the primary outcome analysis participants who were known to have been re-incarcerated (consistent with prior analyses [15]), known to have died, or withdrew consent. Descriptive statistics were used to characterize the population.

Log-binomial regression was used to assess for bivariable and multivariable associations between self-reported linkage to care and verified linkage to care and independent variables. Log-binomial regression was selected to estimate relative risks for a common outcome. All regression analyses included adjustment for facility effect. We assessed the following independent variables: sex, age group $(<35, \geq 35$ years old), CD4 count closest to time of release, duration of incarceration, location of HIV diagnosis, and location of ART initiation. Bivariable analyses were initially performed. Independent variables with a $p \leq 0.1$ in bivariable analyses were included in multivariable model building. Age group and correctional facility were included in all multivariable models regardless of $p$ value. Sex was not included, a priori, in adjusted models due to the relatively small proportion of women in the study. Variables with $p>0.1$ in multivariable modeling were eliminated in a stepwise manner starting with the variable with the highest $p$ value. This process was continued until all selected variables had a $p<0.1$. Through this process we developed final models 
for self-reported linkage to care and for verified linkage to care. Stata 14 was used for all analyses (STATA Corp. College Park, Texas, USA).

\section{Results}

From May 2014 to December 2016, 608 inmates were screened for study eligibility and 554 (91\%) met eligibility criteria. Reasons for ineligibility were not having any contact details for follow-up [6], not receiving HIV care [3], and unknown release date (45). Of the 554 who were eligible, 516 gave consent (93\%). From these, 391 were released on ART. The majority of those not on ART at release were not eligible based on contemporaneous CD4 count criteria. Forty were subsequently excluded from analysis: 5 withdrew participation following release, 28 were known to be re-incarcerated, and 7 were known to have died. The remaining 351 contributed to the analyses. Overall, 301 (86\%) participants were men, the median age was 35 years (interquartile range, [IQR]: 30, 40), and $266(76 \%)$ were initiated on ART during the index incarceration (Table 1).

Follow-up contact was successful with the participant or household member for 257 (73\%) of the participants. Linkage to care within 90 days was reported by 227 (65\%). Based on reported ART supply at correctional facility release and timing of linkage to care, 164 (47\%) participants had no lapse in ART supply. Verification of self-reported linkage to care was successful for 121 (34\%). Among those with verified linkage to care within 90 days (for which we have the most precise linkage dates), $25 \%$ linked within 11 days, $50 \%$ within 28 days, and $75 \%$ within 49 days.

In bivariate log-binomial regression, adjusting for correctional facility, ART initiation during the current incarceration was associated with self-reported linkage to care $(p=0.03)$. Longer duration of incarceration had a trend toward association with self-reported linkage to care $(p=0.06$; Table 2$)$. In adjusted multivariable analysis including age group, longer duration of incarceration and ART initiation during the index incarceration each maintained significance or trended toward a significant association with increased linkage to care (Table 2).

The independent variable significantly associated with increased verified linkage to care was age $>35$ years. Three additional variables trended toward association: HIV diagnosis outside of a correctional center, ART initiation during the index incarceration, and longer duration of incarceration (Table 3). In the final multivariable modeling, adjusted for correctional facility, older age maintained a significant association, site of HIV diagnosis and site of ART initiation maintained a trend toward significance, and duration of incarceration lost significance and was dropped from the model (Table 3).
Table 1 Characteristics of the population

\begin{tabular}{|c|c|}
\hline & n (\%) \\
\hline \multicolumn{2}{|l|}{ Sex } \\
\hline Male & $301(86)$ \\
\hline Female & $50(14)$ \\
\hline \multicolumn{2}{|l|}{ Age group, years } \\
\hline $18-35$ & $196(56)$ \\
\hline$>35$ & $155(44)$ \\
\hline \multicolumn{2}{|l|}{ Country of origin } \\
\hline South Africa & $325(92)$ \\
\hline Lesotho & $3(1)$ \\
\hline Mozambique & $7(2)$ \\
\hline Zimbabwe & $16(4)$ \\
\hline \multicolumn{2}{|c|}{ Place where received HIV diagnosis } \\
\hline Correctional center & $211(60)$ \\
\hline Not within justice system & $134(38)$ \\
\hline Unknown & $6(2)$ \\
\hline \multicolumn{2}{|c|}{ Started ART during index incarceration } \\
\hline No & $85(24)$ \\
\hline Yes & $266(76)$ \\
\hline \multicolumn{2}{|l|}{ Duration of incarceration } \\
\hline$<1$ year & $159(44)$ \\
\hline $1-2$ years & $55(16)$ \\
\hline$>2$ years & $137(39)$ \\
\hline \multicolumn{2}{|c|}{ Last CD4 count prior to release, cells $/ \mathrm{mm}^{3}$} \\
\hline$\leq 200$ & $43(20)$ \\
\hline $201-350$ & $73(33)$ \\
\hline $351-500$ & $48(22)$ \\
\hline$>500$ & $48(22)$ \\
\hline No CD4 count available & $55(25)$ \\
\hline \multicolumn{2}{|l|}{ ART supply provided on release } \\
\hline$<30$ days & $80(23)$ \\
\hline 30-59 days & $96(27)$ \\
\hline $60-89$ days & $51(14)$ \\
\hline$\geq 90$ days & $22(6)$ \\
\hline Missing & $102(29)$ \\
\hline
\end{tabular}

\section{Discussion}

This is the first description from sub-Saharan Africa, of which we are aware, regarding the transition from HIV care in a correctional facility to community clinics. Linkage to care was self-reported by $65 \%$ of participants and could be verified with clinical documentation for $34 \%$. At most, $47 \%$ of participants had no post-release lapse in ART supply. We observed greater self-reported linkage to care and a trend toward greater verified linkage to care among participants initiated on ART while in the correctional facility. These findings demonstrate an 
Table 2 Participant characteristics and association with self-reported care transition $(n=351)$

\begin{tabular}{|c|c|c|c|}
\hline & $n /$ total & $\begin{array}{l}\text { bivariable risk ratio } \\
(95 \% \text { confidence interval) })^{a}\end{array}$ & $\begin{array}{l}\text { multivariable risk ratio } \\
(95 \% \text { confidence interval) }\end{array}$ \\
\hline \multicolumn{4}{|l|}{ Sex } \\
\hline Male & $191 / 301$ & Ref, $p=0.6$ & \\
\hline Female & $36 / 50$ & $1.0(0.86, .13)$ & \\
\hline \multicolumn{4}{|l|}{ Age group, years } \\
\hline $18-35$ & $121 / 196$ & Ref, $p=0.2$ & Ref, $p=0.4$ \\
\hline$>35$ & $106 / 155$ & $1.1(0.96,1.3)$ & $1.1(0.91,1.2)$ \\
\hline \multicolumn{4}{|c|}{ Place where received HIV diagnosis } \\
\hline Correctional center & $130 / 211$ & Ref, $p=0.3$ & \\
\hline Outside correctional center & $93 / 134$ & $1.1(0.94,1.3)$ & \\
\hline \multicolumn{4}{|c|}{ Started ART during index incarceration } \\
\hline No & $46 / 83$ & Ref, $p=0.03$ & Ref, 0.06 \\
\hline Yes & $181 / 268$ & $1.2(1.0,1.5)$ & $1.2(0.99,1.5)$ \\
\hline \multicolumn{4}{|l|}{ Duration of incarceration } \\
\hline$<1$ year & $97 / 159$ & Ref, $p_{\text {trend }}=0.03$ & Ref, $p=0.03$ \\
\hline $1-2$ years & $28 / 55$ & $0.86(0.65,1.2)$ & $0.60(0.46,0.77)$ \\
\hline$>2$ years & $102 / 137$ & $1.2(1.0,1.4)$ & $1.1(0.81,1.3)$ \\
\hline \multicolumn{4}{|c|}{ Last CD4 count prior to release, cells $/ \mathrm{mm}^{3}$} \\
\hline$<=200$ & $29 / 43$ & Ref, $p_{\text {trend }}=0.8$ & \\
\hline $201-350$ & $51 / 73$ & $1.0(0.81,1.3)$ & \\
\hline $351-500$ & $30 / 48$ & $0.95(0.71,1.3)$ & \\
\hline$>500$ & $38 / 55$ & $1.1(0.83,1.4)$ & \\
\hline
\end{tabular}

${ }^{\mathrm{a}}$ Adjusted for correctional facility

overall troubling gap in linkage to care, while also providing important re-assurance that initiating ART within correctional facilities does not exacerbate post-release loss from care.

One prior study from South Africa reported the proportion of community reentrants who continued care at the same off-site community clinic where they had received care during incarceration [9]. In that study, among 34 released inmates, $23(68 \%)$ had at least one visit to the clinic post-release. The substantial changes that have occurred with HIV care in South Africa since the time of that study include expansion of ART services to correctional facilities and changes in ART initiation thresholds from a CD4 count $<200$ cells $/ \mathrm{mm}^{3}$ to universal treatment access [18-20]. Some of these changes may have effected care continuity.

Important research has been completed in high income countries on the transition from corrections to community care. Compared to some of these prior studies, our observed self-reported linkage to care was higher. Specifically, the proportion of ex-inmates linking to care in studies from the United States ranges from 28 to $95 \%$; a median of $36 \%$ was calculated in a metaanalysis $[10-15,21-26]$. There are several possible reasons for the potentially higher linkage to care that we observed. First, we may have over-estimated linkage to care through the use of self-report. Second, health insurance is generally necessary for accessing HIV care in the United States whereas HIV care is free within the public sector in South Africa. Third, substance use can interfere with linkage to care. While substance use is present in South Africa [27], it is likely more prevalent among the corrections population in the United States. Forth, the median duration of incarceration was longer in our study than many reports from the United States, a factor that has been previously associated with an improved care transition [28].

We noted increased verified linkage to care with older age and trends toward association with ART initiated during the index incarceration, HIV diagnosed outside of a correctional center, and longer duration of incarceration. Studies from the United States have consistently reported a similar association between older age and improved linkage to care [29-32]. Several studies have also reported a significant association between longer duration of incarceration and increased linkage to care [28, 29, 32]. One study from the United States reported a trend toward increased linkage to care with HIV diagnosis during the index incarceration in contrast to our finding [31]. We did not find any other studies that 
Table 3 Participant characteristics and association with verified care transition $(n=351)$

\begin{tabular}{|c|c|c|c|}
\hline & $n /$ total & $\begin{array}{l}\text { bivariable risk ratio } \\
(95 \% \text { confidence interval) })^{a}\end{array}$ & $\begin{array}{l}\text { multivariable risk ratio } \\
(95 \% \text { confidence interval) }\end{array}$ \\
\hline \multicolumn{4}{|l|}{ Sex } \\
\hline Male & $105 / 301$ & Ref, $p=0.7$ & \\
\hline Female & $16 / 50$ & $0.92(0.57,1.5)$ & \\
\hline \multicolumn{4}{|l|}{ Age group, years } \\
\hline $18-35$ & $55 / 196$ & Ref, $p=0.004$ & Ref, $p=0.004$ \\
\hline$>35$ & $66 / 155$ & $1.5(1.1,2.0)$ & $1.5(1.1,2.0)$ \\
\hline \multicolumn{4}{|c|}{ Place where received HIV diagnosis } \\
\hline Correctional center & $65 / 211$ & Ref, $p=0.08$ & Ref, $p=0.1$ \\
\hline Outside correctional center & $53 / 134$ & $1.3(0.97,1.7)$ & $1.2(0.93,1.6)$ \\
\hline \multicolumn{4}{|c|}{ Started ART during current incarceration } \\
\hline No & $22 / 83$ & Ref, $p=0.09$ & Ref, $p=0.1$ \\
\hline Yes & $99 / 268$ & $1.4(0.95,2.1)$ & $1.4(0.92,2.0)$ \\
\hline \multicolumn{4}{|l|}{ Duration of incarceration } \\
\hline$<1$ year & $48 / 159$ & Ref, $p_{\text {trend }}=0.1$ & \\
\hline $1-2$ years & $16 / 55$ & $0.97(0.60,1.6)$ & \\
\hline$>2$ years & $57 / 137$ & $1.4(0.99,1.9)$ & \\
\hline \multicolumn{4}{|c|}{ Last CD4 count prior to release, cells $/ \mathrm{mm}^{3}$} \\
\hline$<=200$ & $16 / 43$ & Ref, $p_{\text {trend }}=0.8$ & \\
\hline $201-350$ & $24 / 73$ & $0.61(0.53,1.4)$ & \\
\hline $351-500$ & $21 / 48$ & $1.2(0.71,2.0)$ & \\
\hline$>500$ & $19 / 55$ & $0.94(0.55,1.6)$ & \\
\hline
\end{tabular}

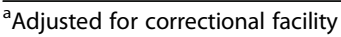

specifically addressed the timing of ART initiation and linkage to care during reentry.

This study has the strengths of recruiting participants while incarcerated and achieving enrollment of a high proportion of those who were eligible. Limitations include failure to determine outcomes for all participants due to the challenge with post-release follow-up. Participants whom we could not trace were more likely to lack a fixed address and not have regular contact with family members. We expect that this population was less likely to have engaged in care following release, although we cannot confirm this. Among those participants who we were able to contact, most reported clinic attendance. Of those reporting going to the clinic, we were only able to verify actual attendance for about $50 \%$. There are several potential reasons for the low level of verification including over-reporting by participants due to the social desirability bias, a phenomenon reported in prior linkage to care studies [6,33,34]. It is also possible that we were unable to identify records for some participants who truly did link to care due to missing records (from electronic and paper clinic records), lack of laboratory testing (for querying electronic laboratory data), and use of pseudonyms by participants either in the study or at a clinic.
Additional considerations are limitations to generalizability. The small sample size and inclusion of correctional facilities in a single region in a single country limit the generalizability to more rural areas and beyond South Africa. In addition, we excluded individuals with expected release beyond the region of the study. It is plausible that linkage to care challenges were greater and linkage to care lower for those released to more distant locations.

\section{Conclusions}

Innovative approaches are needed to monitor and support patients during the transition from correctional facilities to community HIV care in South Africa. Approaches may need to address individual level barriers through individuallevel services and improve system level communication and patient monitoring between correctional health services and community clinics. Given the apparent attrition in HIV care during the corrections to community transition, further operational research is needed to better characterize this transition and identify effective approaches of retaining former inmates in care.

\section{Acknowledgements}

We wish to thank all the participants for their engagement and trust in the research process. We also wish to thank the many correctional service members who provided guidance and assistance for the successful 
completion of this study. Finally we wish to thank the team from CDC for support and study oversight, singling out Dr. Anand Date for enthusiasm and valued input during the study process and Dr. Ehimario Igumbor for his thorough review of a draft manuscript. This manuscript was supported by the President's Emergency Plan for AIDS Relief (PEPFAR) though the U.S. Centers for Disease Control and Prevention (CDC) under terms of Cooperative Agreement number GH000515. Its contents are solely the responsibility of the authors and do not necessarily represent the official views of CDC

\section{Authors' contributions}

TM: data acquisition, data analysis, results interpretation, manuscript drafting; DMW: data analysis, results interpretation, manuscript drafting; GL: data acquisition, results interpretation, manuscript drafting; SN: stakeholder engagement and participatory research facilitation, data acquisition; NM-P: data acquisition, manuscript drafting; SC: results interpretation, manuscript drafting; $\mathrm{CJH}$ : study conception, data analysis, drafting manuscript. All authors reviewed and approved the final version of the manuscript.

\section{Funding}

This manuscript was supported by the President's Emergency Plan for AIDS Relief (PEPFAR) though the U.S. Centers for Disease Control and Prevention (CDC) under terms of Cooperative Agreement number GH000515.

\section{Availability of data and materials}

The data set used for this publication is available upon request from the authors.

\section{Ethics approval and consent to participate}

All participants completed written informed consent prior to enrollment. This study was conducted according to the principles expressed in the Declaration of Helsinki. Human subject research approval was obtained from the University of the Witwatersrand Human Research Ethics Committee (M120492), the South African Department of Correctional Services Research Review Committee, the Johns Hopkins Medicine Institutional Review Board (NA_83335), and the CDC Institutional Review Board.

\section{Consent for publication}

Not applicable.

\section{Competing interests}

The authors declare that they have no competing interests.

\section{Author details \\ ${ }^{1}$ Aurum Institute, Johannesburg, South Africa. ${ }^{2}$ The University of the Witwatersrand School of Public Health, Johannesburg, South Africa. ${ }^{3}$ Johns Hopkins University Bloomberg School of Public Health, Baltimore, USA. ${ }^{4}$ Department of Correctional Services, Gauteng Region, South Africa. ${ }^{5}$ Johns Hopkins University School of Medicine, CRB2 Rm 1M11, 1550 Orleans Rd, Baltimore, MD 21205, USA.}

Received: 3 May 2019 Accepted: 26 February 2020

\section{Published online: 12 March 2020}

\section{References}

1. Organization WH. Consolidated guidelines on HIV prevention, diagnosis, treatment and care for key populations. 2014.

2. Telisinghe L, Charalambous S, Topp SM, Herce ME, Hoffmann CJ, Barron P, et al. HIV and tuberculosis in prisons in sub-Saharan Africa. Lancet. 2016; 388(10050):1215-27.

3. UNAIDS. UNAIDS Data 2017. 2017

4. Govindasamy D, Ford N, Kranzer K. Risk factors, barriers and facilitators for linkage to antiretroviral therapy care: a systematic review. Aids. 2012;26(16): 2059-67.

5. Johnson LF, Rehle TM, Jooste S, Bekker LG. Rates of HIV testing and diagnosis in South Africa: successes and challenges. AIDS. 2015;29(11): 1401-9.

6. Hoffmann CJ, Mabuto T, Ginindza S, Fielding KL, Kubeka G, Dowdy DW, et al. Strategies to accelerate HIV care and antiretroviral therapy initiation after HIV diagnosis: a randomized trial. J Acquir Immune Defic Syndr. 2017; 75(5):540-7.
7. Takuva S, Brown AE, Pillay Y, Delpech V, Puren AJ. The continuum of HIV care in South Africa: implications for achieving the second and third UNAIDS 90-90-90 targets. AIDS. 2017;31(4):545-52.

8. Telisinghe L, Hippner P, Churchyard GJ, Gresak G, Grant AD, Charalambous $\mathrm{S}$, et al. Outcomes of on-site antiretroviral therapy provision in a south African correctional facility. Int J STD AIDS. 2016;27(13):1153-61.

9. Davies NE, Karstaedt AS. Antiretroviral outcomes in south African prisoners: a retrospective cohort analysis. PLoS One. 2012;7(3):e33309.

10. Althoff AL, Zelenev A, Meyer JP, Fu J, Brown SE, Vagenas P, et al. Correlates of retention in HIV care after release from jail: results from a multi-site study. AIDS Behav. 2013;17(Suppl 2):S156-70.

11. Baillargeon JG, Giordano TP, Harzke AJ, Baillargeon G, Rich JD, Paar DP. Enrollment in outpatient care among newly released prison inmates with HIV infection. Public Health Rep. 2010;125(Suppl 1):64-71.

12. Ballargeon J, Giordano TP, Rich JD, Wu ZH, Wells K, Pollock BH, et al. Accessing antiretroviral therapy following release from prison; 2010. p. 848-57.

13. Booker CA, Flygare CT, Solomon L, Ball SW, Pustell MR, Bazerman LB, et al. Linkage to HIV care for jail detainees: findings from detention to the first 30 days after release. AIDS Behav. 2012;17:128-36.

14. Iroh PA, Mayo H, Nijhawan AE. The HIV care Cascade before, during, and after incarceration: a systematic review and data synthesis. Am J Public Health. 2015;105(7):e5-16.

15. Wohl DA, Golin CE, Knight K, Gould M, Carda-Auten J, Groves JS, et al. Randomized controlled trial of an intervention to maintain suppression of HIV Viremia after prison release: the imPACT trial. J Acquir Immune Defic Syndr. 2017;75(1):81-90.

16. Services" C. Department of Correctional Services Annual Report 2015/2016 Financial year. Pretoria: Republic of South Africa: Department of Correctional Services; 2016

17. SANDOH. Guidelines for the management of Tuberculosis, Human Immunodeficiency Virus and Sexually-Transmitted Infections in Correctional Centres. 2013.

18. SANDOH. The South African Antiretroviral Treatement Guidelines. 2010.

19. SANDOH. National Consolidated Guidelines for PMTCT an management of HIV in children, adolescents and adults. 2015.

20. SANAC. Let Our Actions Count: South Africa's National Strategic Plan for HIV, TB and STIs 2017-2022. 2017.

21. Golin CE, Knight K, Carda-Auten J, Gould M, Groves J, White BL, et al. Individuals motivated to participate in adherence, care and treatment (imPACT): development of a multi-component intervention to help HIVinfected recently incarcerated individuals link and adhere to HIV care. BMC Public Health. 2016;16:935.

22. Khawcharoenporn T, Zawitz C, Young JD, Kessler HA. Continuity of care in a cohort of HIV-infected former jail detainees. J Correct Health Care. 2013;19(1):36-42.

23. MacGowan RJ, Lifshay J, Mizuno Y, Johnson WD, McCormick L, Zack B. Positive transitions (POST): evaluation of an HIV prevention intervention for HIV-positive persons releasing from correctional facilities. AIDS Behav. 2015;19(6):1061-9.

24. Nunn A, Cornwall A, Fu J, Bazerman L, Loewenthal H, Beckwith C. Linking HIV-positive jail inmates to treatment, care, and social services after release: results from a qualitative assessment of the COMPASS program. J Urban Health. 2010;87(6):954-68.

25. Reznick OG, McCartney K, Gregorich SE, Zack B, Feaster DJ. An ecosystembased intervention to reduce HIV transmission risk and increase medication adherence among inmates being released to the community. J Correct Health Care. 2013;19(3):178-93.

26. Wohl DA, Scheyett A, Golin CE, White B, Matuszewski J, Bowling M, et al. Intensive case management before and after prison release is no more effective thann comprehensive pre-release discharge planning in linking HIV-infected prisoners to care: a randomized trial; 2010. p. 356-64.

27. Dos Santos MM, Trautmann F, Wolvaardt G, Palakatsela R. Rapid Assessment Response (RAR) study: drug use, health and systemic risks--Emthonjeni Correctional Centre, Pretoria, South Africa. Harm Reduct J. 2014;11:11.

28. Loeliger KB, Altice FL, Desai MM, Ciarleglio MM, Gallagher C, Meyer JP. Predictors of linkage to HIV care and viral suppression after release from jails and prisons: a retrospective cohort study. Lancet HIV. 2018;5(2):e96-e106.

29. Baillargeon J, Giordano TP, Rich JD, Wu ZH, Wells K, Pollock BH, et al. Accessing antiretroviral therapy following release from prison. JAMA. 2009; 301(8):848-57.

30. Booker CA, Flygare CT, Solomon L, Ball SW, Pustell MR, Bazerman LB, et al. Linkage to HIV care for jail detainees: findings from detention to the first 30 days after release. AIDS Behav. 2013;17(Suppl 2):S128-36. 
31. Loeliger KB, Meyer JP, Desai MM, Ciarleglio MM, Gallagher C, Altice FL. Retention in HIV care during the 3 years following release from incarceration: a cohort study. PLoS Med. 2018;15(10):e1002667.

32. Ammon B, Iroh P, Tiruneh Y, Li X, Montague BT, Rich JD, et al. HIV care after jail: low rates of engagement in a vulnerable population. J Urban Health. 2018;95(4):488-98.

33. Genberg BL, Naanyu V, Wachira J, Hogan JW, Sang E, Nyambura M, et al. Linkage to and engagement in HIV care in western Kenya: an observational study using population-based estimates from home-based counselling and testing. Lancet HIV. 2015;2(1):e20-6.

34. Mackellar DA, Williams D, Storer N, Okello V, Azih C, Drummond J, et al. Enrollment in HIV care two years after HIV diagnosis in the Kingdom of Swaziland: an evaluation of a National Program of new linkage procedures. PLoS One. 2016;11(2):e0150086.

\section{Publisher's Note}

Springer Nature remains neutral with regard to jurisdictional claims in published maps and institutional affiliations.

Ready to submit your research? Choose BMC and benefit from:

- fast, convenient online submission

- thorough peer review by experienced researchers in your field

- rapid publication on acceptance

- support for research data, including large and complex data types

- gold Open Access which fosters wider collaboration and increased citations

- maximum visibility for your research: over $100 \mathrm{M}$ website views per year

At BMC, research is always in progress.

Learn more biomedcentral.com/submissions 